\title{
Effect of Strain Rate on the Tensile Mechanical Properties of Electron Beam Welded OFE Copper and High-Purity Niobium for SRF Applications
}

\author{
J.-F. Croteau ${ }^{1,4} \cdot$ M. Peroni ${ }^{2} \cdot$ S. Atieh ${ }^{3} \cdot$ N. Jacques ${ }^{4} \cdot$ E. Cantergiani ${ }^{1,5}$ (D)
}

Received: 26 November 2020 / Accepted: 28 January 2021 / Published online: 18 February 2021

(c) The Author(s) 2021

\begin{abstract}
An investigation of the tensile mechanical properties of electron beam welded OFE copper and high-purity niobium sheets is presented. Specimens were deformed in tension at strain rates ranging from $10^{-3}$ to $\sim 1600 \mathrm{~s}^{-1}$. The $0.2 \%$ yield stress and ultimate tensile strength (UTS) of the welded niobium specimens are similar to those of unwelded specimens at strain rates lower or equal to $20 \mathrm{~s}^{-1}$. At higher strain rates, these mechanical properties are lower for welded niobium specimens. The $0.2 \%$ yield stress of welded OFE copper specimens is consistently lower than unwelded specimens over the range of strain rates studied, while the UTS is comparable at all strain rates. The elongation to failure of welded OFE copper specimens remains unchanged at all strain rates while the ductility of niobium specimens reduces at strain rates greater or equal to $20 \mathrm{~s}^{-1}$ and reaches a minimum at $\sim 400 \mathrm{~s}^{-1}$. The effects of the weld on a non-standardized short specimen geometry, developed for this study to obtain strain rates in the order of $10^{3} \mathrm{~s}^{-1}$, are more pronounced for niobium due to large grain sizes (up to $1200 \mu \mathrm{m}$ ) in the fusion region. However, comparable strength and ductility trends, with respect to a standard specimen, were measured at low strain rates. The conservation of strength and the relatively high ductility of the welded sheets, especially for OFE copper, suggest that bent and electron beam welded tubes could be used for the fabrication of seamless superconducting radiofrequency (SRF) cavities. These results are promising for the use of high-speed forming techniques, like electro-hydraulic forming, for the manufacturing of parts using welded tubes and sheets.
\end{abstract}

Keywords Stress/strain measurements $\cdot$ Electron beam welding $\cdot$ SRF $\cdot$ High strain rate $\cdot$ Niobium $\cdot$ OFE copper

\section{Introduction}

Seamless superconducting radiofrequency (SRF) cavities have been proposed to improve performances (i.e. higher quality factor $\left(Q_{0}=\omega_{0} U / P_{\text {loss }}\right.$, where $\omega_{0}$ is the resonant frequency of the cavity, $U$ is the stored energy, and $P_{l o s s}$ is

\footnotetext{
E. Cantergiani

e.cantergiani@mpie.de

1 I-Cube Research/Bmax, 30 boulevard de Thibaud, 31104 Toulouse, France

2 European Commission, Joint Research Centre, Ispra, Italy

3 European Organization for Nuclear Research (CERN), 1211 Geneva, Switzerland

4 ENSTA Bretagne, UMR CNRS 6027, IRDL, 2 rue François Verny, 29806 Brest Cedex 9, France

5 Present Address: Max-Planck-Institut Für Eisenforschung, Max-Planck-Straße 1, 40237 Düsseldorf, Germany
}

the power dissipated in the walls of the cavity), equivalent to a lower surface resistance, for an accelerating gradient of up to $25 \mathrm{MV} / \mathrm{m}$ or more) and reduce the risk of quench in the vicinity of the equatorial weld [1-3], caused by a loss of superconductivity. The role of an SRF cavity, schematically shown in Fig. 1a, is to accelerate charged particles, such as electrons or protons, close to the speed of light in a particle accelerator to generate high energy collisions for fundamental research in particle physics, like the discovery of the Higgs boson at the Large Hadron Collider [4]. During the manufacturing of a $1300 \mathrm{MHz}$ seamless cavity, as shown in Fig. 1b, a high ductility is required since the diameter of a high-purity copper or niobium tube, with an initial inner diameter of $123-150 \mathrm{~mm}$, is reduced to $70 \mathrm{~mm}$ to form the iris and expanded, often with hydroforming, to about $205 \mathrm{~mm}$ at the equator [5, 6]. Seamless cavities have successfully been fabricated for different resonance frequencies at multiple research institutes, universities and companies [5-14]. However, 


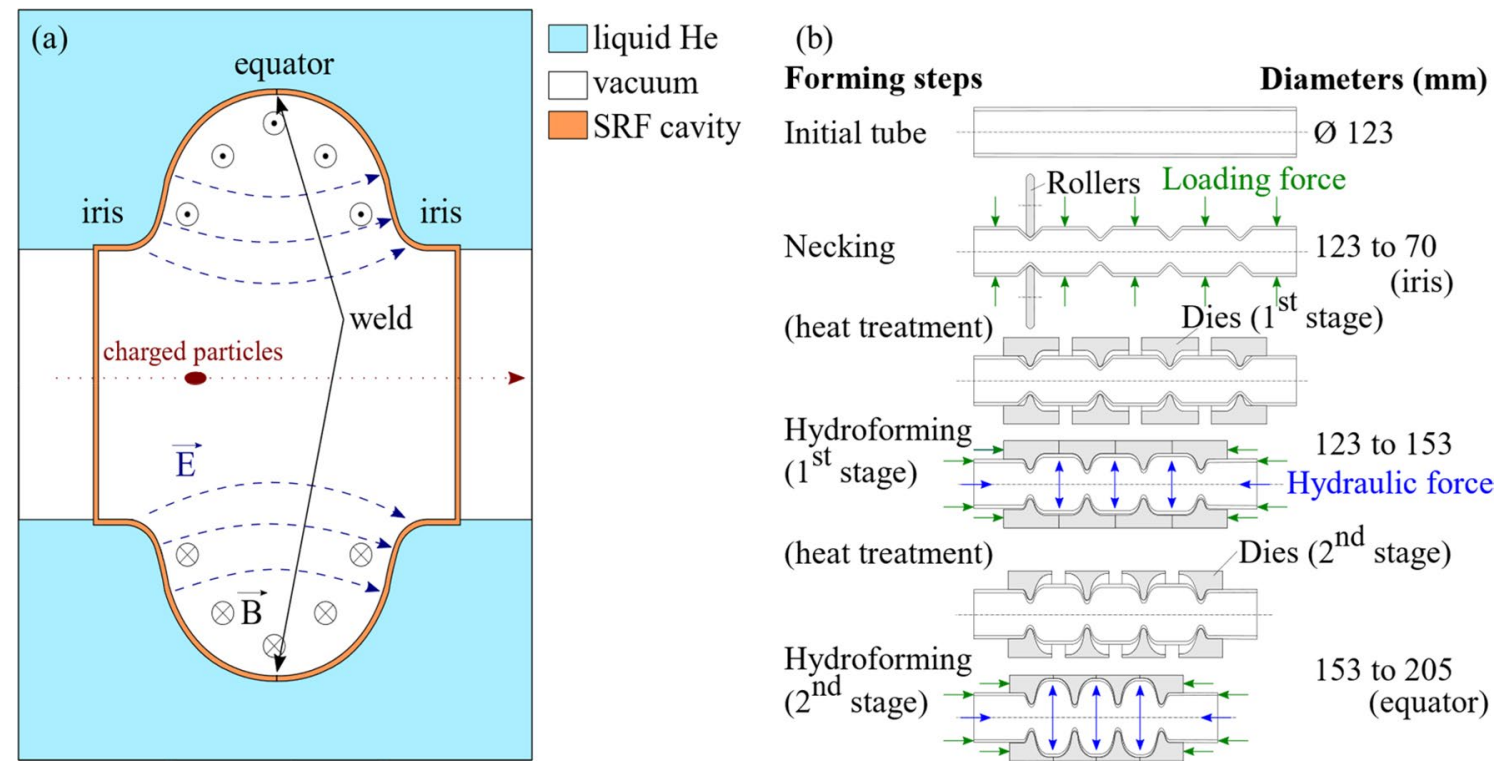

Fig. 1 a Schematic of the cross-section of a typical single-cell SRF cavity with important elements and $\mathbf{b}$ the necking and hydroforming steps used at Japan's High Energy Accelerator Research Organization (KEK) to manufacture seamless $1300 \mathrm{MHz}$ SRF cavities (redrawn from [5])

tubes often have anisotropic properties $[6,15,16]$ or low ductility if they are produced by equal channel angular extrusion (ECAE) [6, 17-20]. The fabrication of tubes using a bent and electron beam (EB) welded sheet has been proposed as the isotropic properties of the sheets are expected to be conserved in the majority of the tube and the weld will only cross the equator at a single location. However, the large grains in the fusion and heat affected zones (HAZ) reduced the ductility at low strain rates for tubes manufactured by the Legnaro National Laboratories of the Italian Institute of Nuclear Physics (INFN LNL) and Deutsches Elektronen-Synchrotron (DESY) [6, 21]. A small tube, with an external diameter of $38 \mathrm{~mm}$, was also produced by EB welding of a bent $2 \mathrm{~mm}$ thick polycrystalline niobium sheet, which was then heat treated to grow large grains, and finally deformed with hydroforming at Michigan State University (MSU) [22]. The tube failed inside a large grain near the weld, had anisotropic properties, and a low ductility.

High-speed sheet forming with technologies such as electro-hydraulic forming (EHF) could be beneficial for this application as the occurrence of plastic flow localization is delayed and the strain to failure in some metals is increased during expansion [23, 24] or due to complex stress state at the sheet-die interaction $[25,26]$. In addition, the performances of SRF cavities formed at high strain rate with EHF and with an oxygen-free electronic (OFE) copper substrate coated with niobium were higher than traditionally spun and machined cavities [27]. The damaged layer is thinner, the shape accuracy is higher, and there is no need for intermediate annealing heat treatments for niobium cavities formed with EHF compared with conventional low strain rate techniques [28].

The mechanical properties of EB welded high-purity niobium specimens have been measured in tension at CERN and at MSU by Jiang et al. [29] at quasi-static nominal strain rates of $\sim 3 \times 10^{-4} \mathrm{~s}^{-1}$, but never at intermediate or high strain rates. Jiang et al. [29] reported a yield stress similar to unwelded specimens and a lower strain hardening in the fusion region.

Compared with alloys, e.g. dual-phase steels [30], highpurity copper and niobium are single phase metals with low content of substitutional and interstitial atoms. The weld and HAZ are then expected to have the same phase and composition as the parent material and strain heterogeneities are expected to be caused only by different grain sizes.

To the best of our knowledge, the mechanical properties of EB welded OFE copper and high-purity niobium at strain rates greater than the quasi-static regime, i.e. in the $10^{-4}-10^{-3} \mathrm{~s}^{-1}$ range, are not documented in the literature. In the present study, the yield and tensile strengths and ductility of both materials are investigated at strain rates between $10^{-3} \mathrm{~s}^{-1}$ and approximately $10^{3} \mathrm{~s}^{-1}$ and compared with data of unwelded specimens tested at similar strain rates. The objectives are to quantify and understand the effect of strain rate on the mechanical properties of EB welded OFE copper and high-purity niobium for the fabrication of seamless SRF cavities from a bent and EB welded tube using a high-speed sheet forming technique. 


\section{Materials and Methods}

\section{Materials}

Oxygen-free electronic (OFE) copper (ASTM C10100 [31]) and high-purity niobium (residual-resistivity ratio $($ RRR $)>300$ ) sheets are studied. Both materials are used as substrates in the fabrication of superconducting radiofrequency (SRF) cavities. Sheets with an initial thickness of $4 \mathrm{~mm}$ were electron beam welded at CERN with one pass on each side of the sheet using the same electron beam parameters (accelerating voltage of $100 \mathrm{kV}$, current of $22-23 \mathrm{~mA}$, workpiece distance of $400 \mathrm{~mm}$, and beam speed of $600 \mathrm{~mm} /$ $\mathrm{min})$. Compared with other reported EB welding parameters for high-purity niobium [7, 29, 32-35], the welding energyto-sheet thickness ratio is lower. However, a full penetration was observed at CERN in previous internal studies with similar welding energies. The top and bottom surfaces of the welded sheets were milled to remove surface defects produced during welding and obtain flat surfaces. Tensile specimens were cut using wire electro-discharge machining (EDM). The weld was located at the center of the gage section and perpendicular to the tensile direction, as specified in the ISO 4136:2012 standard [36]. OFE copper specimens were annealed at $600{ }^{\circ} \mathrm{C}$ for $2 \mathrm{~h}$ in vacuum after EB welding. The machining and annealing steps were performed to be representative of material conditions during sheet forming of crab cavities [37] and for future seamless SRF cavities using bent and EB welded tubes.

\section{Hardness Measurements and Microstructure Analysis}

Hardness was measured across the weld of the cross-section of polished specimens using a Vickers indenter and a load of $200 \mathrm{gf}(\sim 1.96 \mathrm{~N})$ applied for $10 \mathrm{~s}$. Measurements were taken in the parent material, HAZ, and fusion zone.

The cross-section of undeformed EB welded specimens were polished and etched for microstructure analysis with an optical microscope. Copper was etched with a solution of $5 \mathrm{~g}$ $\mathrm{FeCl}_{3}, 50 \mathrm{~mL} \mathrm{HCl}$ and $100 \mathrm{~mL} \mathrm{H}_{2} \mathrm{O}$ and niobium was etched with a solution of $15 \mathrm{~mL} \mathrm{HF}, 35 \mathrm{~mL} \mathrm{HNO}_{3}$, and $75 \mathrm{~mL} \mathrm{H}_{2} \mathrm{O}$.

\section{Specimen Geometries and Tensile Tests}

Tensile tests were performed at room temperature and at nominal strain rates of $2.0 \times 10^{-3} \mathrm{~s}^{-1}$ to $20 \mathrm{~s}^{-1}$ with a servohydraulic machine (MTS 810) and with tensile split Hopkinson bars for strain rates of $400 \mathrm{~s}^{-1}$ to $1600 \mathrm{~s}^{-1}$. Figure 2 shows the two specimen geometries used with their main dimensions. A long tensile specimen, respecting ASTM E8

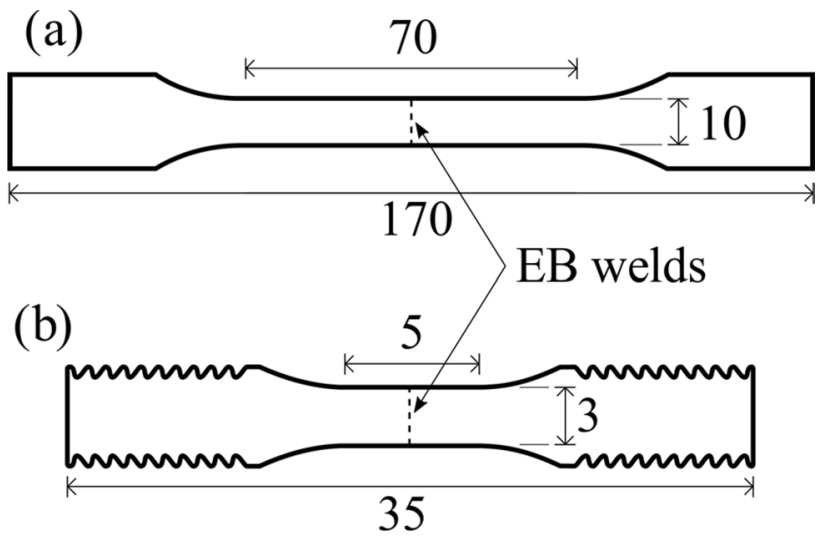

Fig. 2 Geometry and main dimensions (in $\mathrm{mm}$ ) of the a long and b short EB welded specimens. The thickness of both specimens is about $3.96 \mathrm{~mm}$

standard [38], was used for tests at quasi-static strain rates $\left(10^{-3} \mathrm{~s}^{-1}\right.$ to $\left.10^{-1} \mathrm{~s}^{-1}\right)$. A shorter specimen with a rectangular cross-section was specifically designed for tests at high strain rates with split Hopkinson bars. The short specimen was tested over the entire range of strain rates $\left(2.0 \times 10^{-3} \mathrm{~s}^{-1}\right.$ to $\sim 1600 \mathrm{~s}^{-1}$ ). To assess that the stress state in the novel specimens is close to uniaxial tension, preliminary tests with unwelded OFE copper and finite element computations were carried out. They showed that stress triaxiality components are negligible and the pre-necking mechanical properties are the same as the standard specimen. This is also confirmed in "Results and Discussions" section for welded specimens deformed at strain rates in the order of $10^{-3} \mathrm{~s}^{-1}$ and $10^{-1} \mathrm{~s}^{-1}$.

Specimens were painted in the gage section with a uniform matte white paint layer and black speckles. The stochastic paint pattern was used with $2 \mathrm{D}$ digital image correlation (DIC) to measure local deformations and specimen elongation in the gage section to calculate the engineering strain. DIC analyses were performed with the commercial software package GOM Correlate, with average subset size and point distance of $248 \mu \mathrm{m}$ and $123 \mu \mathrm{m}$, respectively, for tests at strain rates lower or equal to $20 \mathrm{~s}^{-1}$ and $437 \mu \mathrm{m}$ and $136 \mu \mathrm{m}$, respectively, at higher strain rates. The influence of out-of-plane displacements in the neck on 2D DIC measurements was minimized by calculating the engineering strain of the specimens using the change in distance between two points located about $2.5 \mathrm{~mm}$ on either side of the weld (see "Mechanical Properties" section for more details). Pictures of the specimens were acquired with a hybrid CCD/ CMOS camera (pco.edge 5.5) for strain rates lower or equal to $2.0 \times 10^{-1} \mathrm{~s}^{-1}$ and with two high-speed cameras for higher strain rates (IDT OS8-S3 in MTS 810 tests and Photron FASTCAM SA1.1 in Hopkinson bar tests). 


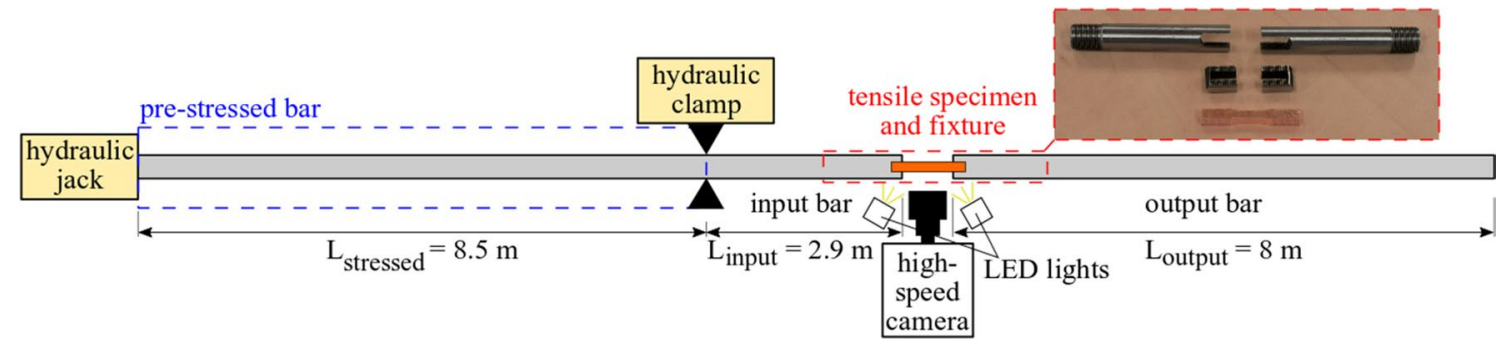

Fig. 3 Schematic of the split Hopkinson bars system developed at the HopLab for tensile tests at high strain rates [39]. (Inset) OFE copper tensile specimen, adaptors to align the specimen with the center of the bars, and holders with threaded ends to fix the assembly on the input and output bars
Fig. 4 Vickers microhardness at different locations along niobium and OFE copper crosssections

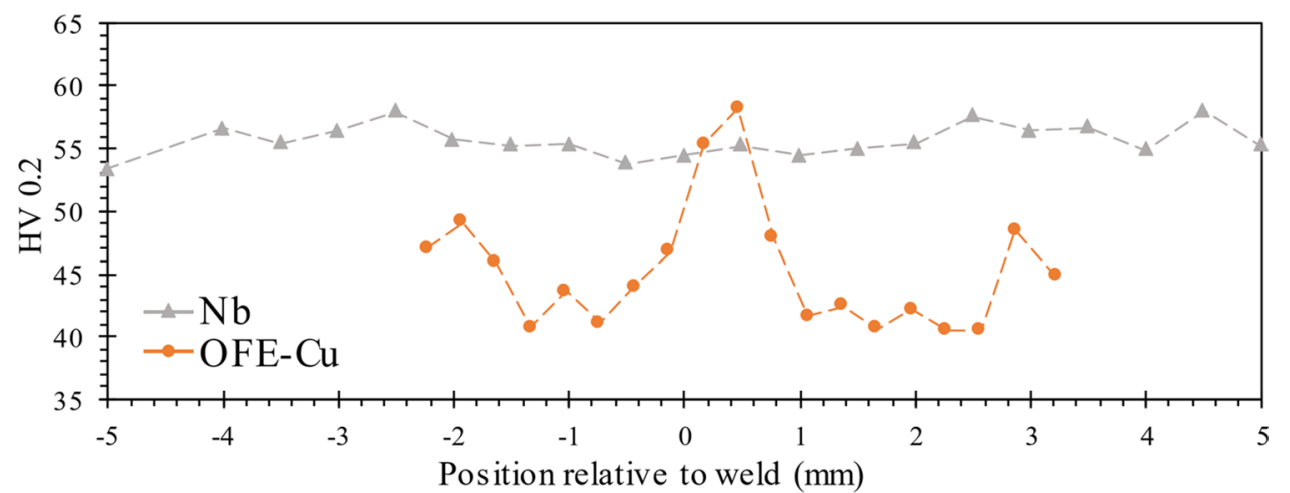

Tensile split Hopkinson tests were performed using a bar apparatus designed at the Hopkinson bar laboratory (HopLab) of the European Commission Joint Research Centre (JRC). The input and output bars were made of $17-4 \mathrm{H}$ stainless steel $\left(E=197 \mathrm{GPa}, \rho=7780 \mathrm{~kg} / \mathrm{m}^{3}\right.$, and $\varnothing=10 \mathrm{~mm}$ ) with lengths specified in the diagram shown in Fig. 3. Compared with traditional split Hopkinson bar systems, the tensile strain pulse is not generated by projecting a striker bar, but by pre-straining a section of the input bar $[39,40]$. A hydraulic jack was used to prestrain the bar and a hydraulic clamp was used to hold and release the strain pulse, as shown in Fig. 3. The strain pulse was sufficiently long to deform the specimens up to failure. It was measured using three strain gages on both the input and output bars. The resulting strain rate was approximately constant until necking for niobium and decreasing by about $30-40 \%$ for copper. However, the long strain pulse, with respect to the bar length, resulted in overlapping incident, reflected, and transmitted waves in the sections of the bars with the strain-gages. Therefore, the algorithm proposed by Bussac et al. [41] to separate the waves traveling in different directions was used. This technique requires at least two independent strain measurements per bar and allows the reconstruction of the strain history at any location in the bars. More details about the implementation of this technique are found in the work of Peroni et al. [42].

\section{Results and Discussions}

\section{Hardness Measurements and Microstructure Analysis}

Figure 4 shows the Vickers microhardness profile of niobium and OFE copper as a function of the distance from the weld. The hardness of niobium is nearly constant in the fusion zone, the HAZ, and the parent material (variations between 53 HV 0.2 and 58 HV 0.2). Similar values were obtained by Jiang et al. [29] who measured a higher hardness in the HAZ (55 HV 0.3 to $60 \mathrm{HV} \mathrm{0.3)} \mathrm{compared} \mathrm{with} \mathrm{regions} \mathrm{taken}$ more than $80 \mathrm{~mm}$ away from the weld center ( $49 \mathrm{HV} 0.3$ to $55 \mathrm{HV} 0.3$ ). The nearly constant hardness is consistent with the high-purity of the material and the low contamination during EB welding, due to the vacuum in the chamber. A larger variation in hardness was measured in the OFE copper specimen. The hardness is highest in the fusion zone, with a maximum of $58.2 \mathrm{HV} 0.2$, lowest in the HAZ with an average of $41.5 \mathrm{HV} 0.2$, and intermediate in the parent material of the specimen, with an average of 47.1 HV 0.2. The higher hardness in the fusion zone could be due to a combination 


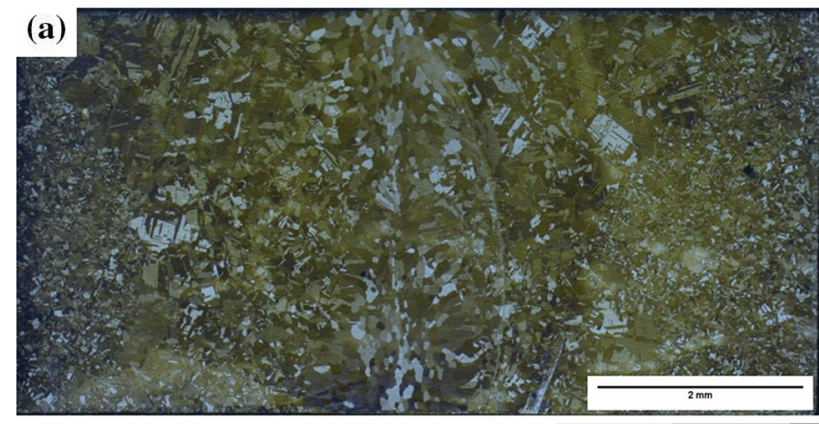

(b)

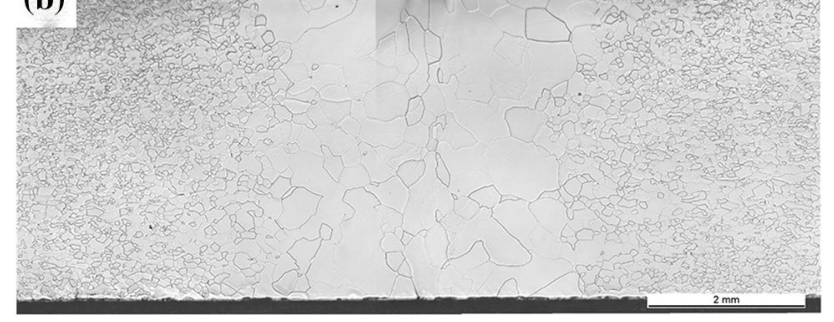

Fig. 5 Microstructure of the cross-section of etched a OFE copper and $\mathbf{b}$ niobium specimens. The weld is approximately at the center of the pictures

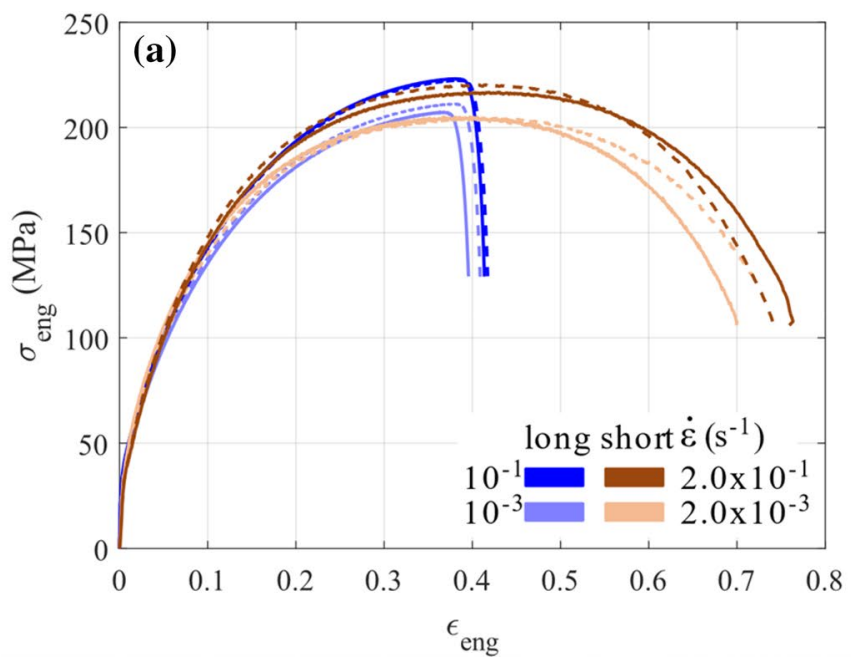

Figure 5 shows the etched microstructure in the cross-section of welded OFE copper and niobium specimens revealing grains and annealing twins. The grains in the HAZ of the OFE copper specimen are larger than in the parent material and the fusion zone. Annealing twins are also visible in the HAZ and parent material, but not in the center of the weld, where the grains have smoother edges and often converge to a region where crystal nucleation likely started. The niobium specimen, shown in Fig. 5b, has much larger grains close to center of the weld and in the HAZ (500-1200 $\mu \mathrm{m})$, compared to the parent material (20-200 $\mu \mathrm{m})$. Similar grain dimensions were measured by Jiang et al. for EB butt welds of high-purity niobium [29].

\section{Mechanical Properties}

The engineering stress-strain curves of the short and long specimens are compared in Fig. 6 for quasi-static strain rates at the same order of magnitude $\left(10^{-3} \mathrm{~s}^{-1}\right.$ and $10^{-1} \mathrm{~s}^{-1}$ ) and similar mechanical properties are measured pre-necking, i.e. before the nominal stress reaches its maximum value. The strain of the small specimens

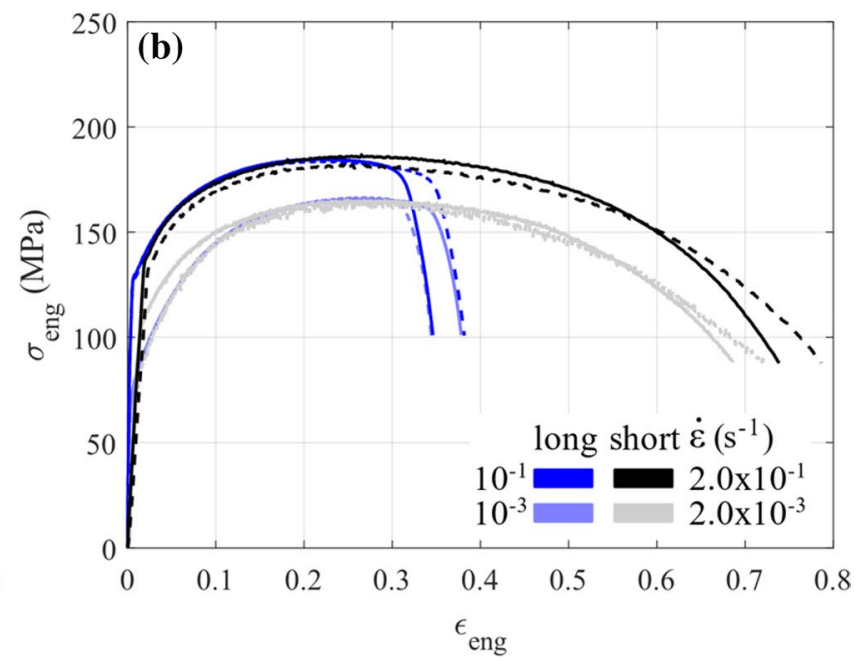

Fig. 6 Comparison of the tensile mechanical properties of the short and long specimen geometries for EB welded a OFE copper and $\mathbf{b}$ niobium specimens. Dashed lines represent the repetition of a test performed at the same strain rate

of multiple factors such as a recrystallized microstructure with smaller grains [43] and residual stresses induced by the welding process $[44,45]$ and not completely removed by the post-welding annealing heat treatment. Despite the heterogeneous hardness properties in the fusion zone, the measured tensile mechanical properties, i.e. the stress-strain curves up to necking, are similar to unwelded specimens ("Mechanical Properties" section) and fracture occurred in the region of the fusion zone ("Strain Heterogeneities and Necking" section). was calculated using DIC by measuring the displacement between two points that were initially separated by about $5 \mathrm{~mm}$ and using the displacement of the cross-head of the tensile machine for the long specimens. The initial gage length of $5 \mathrm{~mm}$ was selected based on finite element modelling of the quasi-static tensile test of an unwelded OFE copper specimen using known material properties. The stress-strain curve was calculated using the output force and displacement of the specimen from the simulation 

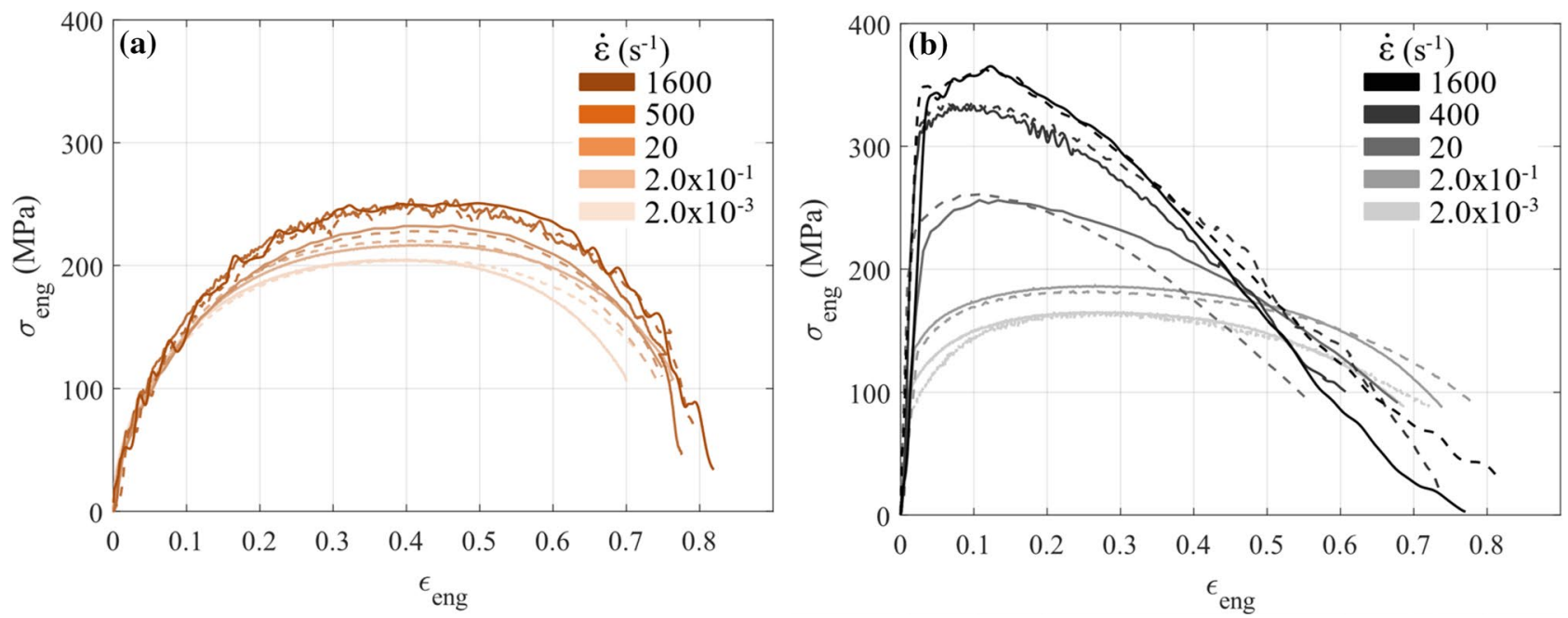

Fig. 7 Engineering stress-strain curves of EB welded a OFE copper and b niobium for short specimens deformed at strain rates between $2.0 \times 10^{-3} \mathrm{~s}^{-1}$ and $\sim 1600 \mathrm{~s}^{-1}$. Dashed lines represent the repetition of a test performed at the same strain rate

for a given gage length and compared with the expected response. The similarities in mechanical properties for the long and short specimens confirm that the methodology using DIC and the short specimen geometry are appropriate to characterize the tensile mechanical properties (yield stress and ultimate tensile stress) of welded specimens.

Figure 7 shows the engineering stress-strain curves of OFE copper and niobium for the short specimen geometry at strain rates of $2.0 \times 10^{-3} \mathrm{~s}^{-1}$ to $\sim 1600 \mathrm{~s}^{-1}$. DIC was used for all tests to ensure consistent strain measurements between tests performed with the servo-hydraulic tensile machine $\left(\dot{\varepsilon} \leq 20 \mathrm{~s}^{-1}\right)$ and the split Hopkinson bars and to measure the strain in the gage length only.

The strain rate sensitivity of EB welded copper and niobium are typical of FCC and BCC metals, respectively. The $0.2 \%$ yield stress of OFE copper specimens is nearly constant at all strain rates and the flow stress slightly increases for increasing strain rate due to increases in strain hardening, as shown in Fig. 7a. Note that the $0.2 \%$ yield stress was calculated using the apparent elastic modulus in the linear section of the stress-strain curve. However, the end of the elastic domain is ill-defined for OFE copper since parabolic hardening gradually increases from a low stress. The yield stress of high-purity niobium strongly increases for increasing strain rates (Fig. 7b). The apparent hardening rate observed in the engineering stress-strain curve decreases and the ultimate tensile stress is reached at a lower strain for increasing strain rate. A similar increase in yield stress and reduction of the apparent hardening was obtained by Peroni and Scapin [46] for unwelded high-purity niobium specimens and by Croteau et al. [47] for niobium single crystals.

\section{Tensile Strength Strain Rate Sensitivity}

Figure 8 shows the yield stress (YS) and ultimate tensile stress (UTS) as function of strain rate (denoted by $\dot{\varepsilon}$ hereafter) for OFE copper and high-purity niobium for the short (for $2.0 \times 10^{-3} \mathrm{~s}^{-1} \leq \dot{\varepsilon} \leq \sim 1600 \mathrm{~s}^{-1}$ ) and long (for $10^{-3} \mathrm{~s}^{-1} \leq$ $\dot{\varepsilon} \leq 10^{-1} \mathrm{~s}^{-1}$ ) EB welded specimens. The same marker is used for both geometries since similar values are measured at strain rates of the same order of magnitude. The stresses of the welded specimens are compared with those of unwelded specimens from Peroni and Scapin [46] for niobium and from unpublished results obtained by the authors and collaborators from the Imperial College London for OFE copper. The UTS is very similar for the welded and unwelded specimens for both materials at strain rates between $10^{-3} \mathrm{~s}^{-1}$ and $20 \mathrm{~s}^{-1}$. The yield stress is, however, lower by approximately $10 \mathrm{MPa}$ to $18 \mathrm{MPa}$ for the welded OFE copper specimens and within the dispersion of the data for the niobium specimens, for the same strain rate range.

The tensile strength is likely preserved after EB welding due to the high-purity of the parent materials and the low contamination during the welding process. Recall that highpurity OFE copper and niobium have microstructures with a single phase and the welds are performed under vacuum. The welded microstructures are then still composed of a single phase, but with different grain sizes, as described in "Hardness Measurements and Microstructure Analysis" section. Thus, the conservation of mechanical properties is different from what is found for other materials, e.g. high strength low alloy (HSLA) steel, that can have lower and higher tensile strengths for different compositions, welding techniques, and welding parameters [48, 49]. 
Fig. 8 UTS and $0.2 \%$ yield stress as function of strain rate for $\mathbf{a}$ OFE copper and $\mathbf{b}$ niobium EB welded specimens compared with unwelded specimens [46]. Light shaded lines show the strain rate sensitivity $(m)$ of the yield stress
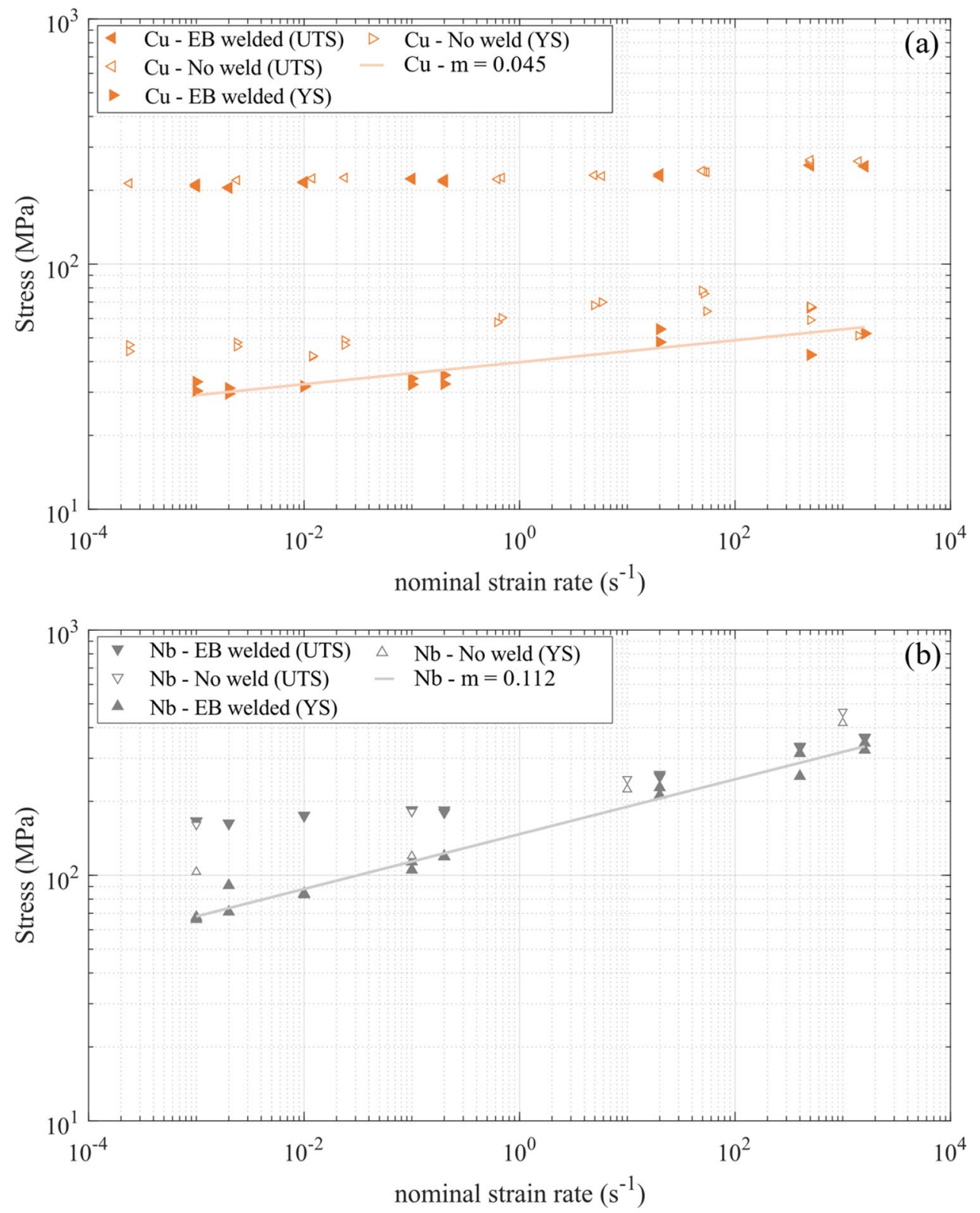

The strain rate sensitivity at yield $\left(m=\partial \ln \sigma_{y} / \partial \ln \dot{\varepsilon}\right)$ is approximately constant for both materials and equal to 0.045 for OFE copper and to 0.112 for niobium. A constant strain rate sensitivity at all strain rates in the range studied, shown with two light shaded straight lines in Fig. 8a and b, indicates that the same dominant deformation mechanism operates at all strain rates. Since the strain rate sensitivity $m$ is derived from a power law relationship $\left(\sigma_{y} \propto \dot{\varepsilon}^{m}\right)$, the use of a log-log plot is more appropriate in the stress as function of strain rate plot to show the differences in $m$ between different materials. A linear scale is often used in literature for the stress axis, but could lead to the false impression that a sudden increase in flow stress is measured at the highest strain rate. The apparent "upturn" in flow stress at strain rates between $\sim 10^{3}$ and $10^{4} \mathrm{~s}^{-1}$ has been contradicted for few materials and reviewed by Rosenberg et al. [50]. While this upturn phenomenon is not happening in this study, mainly because the highest strain rate is too low, the authors still want to stress the importance of using a logarithmic scale to clearly see changes in strain rate sensitivity $m$ and in activation volume $\left(v^{*} \propto m^{-1}\right)$, which are caused by a change in deformation mechanism [51], e.g. from thermal activation to dislocation drag.

A reduction in absolute difference in stress between the UTS and the YS ( $\left.\Delta \sigma=\sigma_{\mathrm{UTS}}-\sigma_{y}\right)$ is measured for niobium for increasing strain rates, from approximately $99.3 \mathrm{MPa}$ at $10^{-3} \mathrm{~s}^{-1}$ to $28.8 \mathrm{MPa}$ at $\sim 1600 \mathrm{~s}^{-1}$. This is explained by the lower apparent strain hardening rate (in engineering stress-strain curves) for specimens tested at a higher strain rate. This behavior is typical for BCC metals, see for 
Fig. 9 Nominal strain to failure measured with the DIC for short EB welded OFE copper and niobium specimens for strain rates of $2.0 \times 10^{-3} \mathrm{~s}^{-1}$ to approximately $1600 \mathrm{~s}^{-1}$. Dashed lines are used to show trends by connecting the average nominal strain to failure at each strain rate

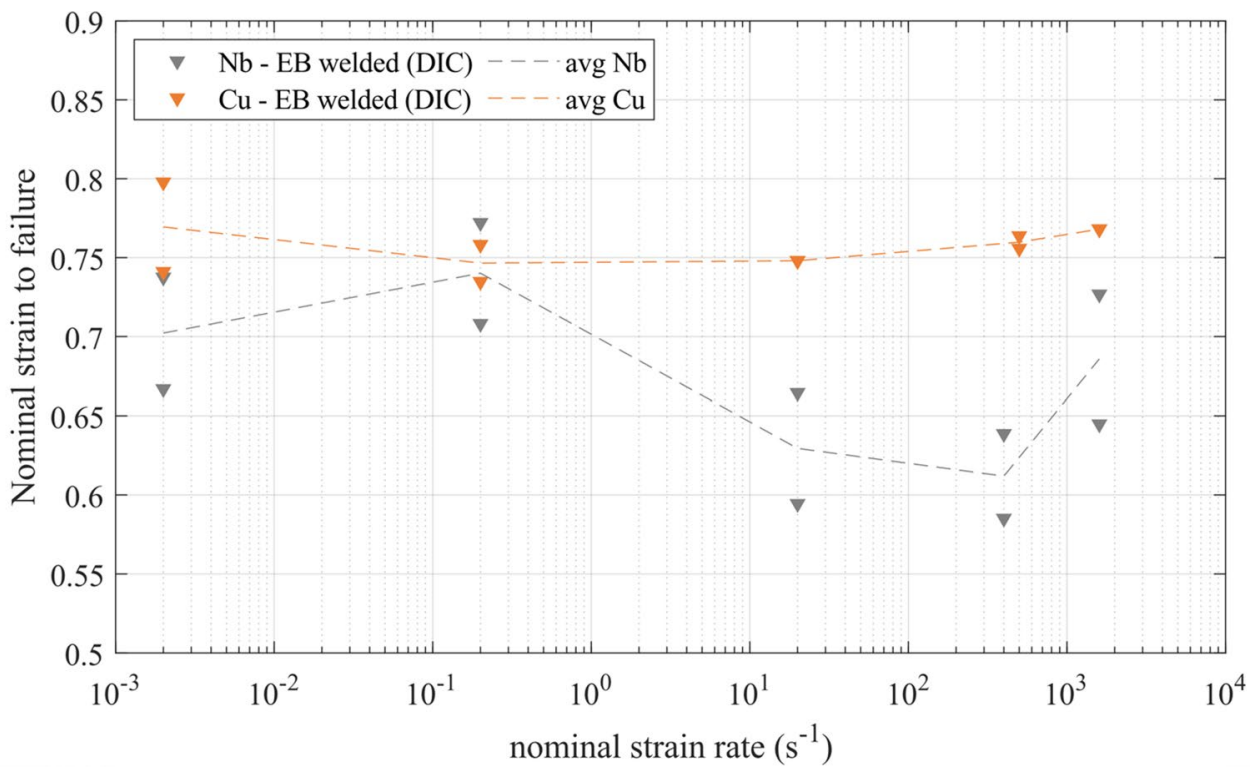

instance the analysis conducted by Zerilli and Armstrong [52] using dislocation mechanics arguments. For OFE copper, a small increase in $\Delta \sigma$ from $\sim 177.6 \mathrm{MPa}$ at $10^{-3} \mathrm{~s}^{-1}$ to $\sim 198.6 \mathrm{MPa}$ at about $1600 \mathrm{~s}^{-1}$ is measured and due to an increasing strain hardening rate for increasing strain rates.

\section{Ductility Strain Rate Sensitivity}

As previously mentioned, and shown in Fig. 6, the postnecking behavior of the long and short specimens is different for similar strain rates. Higher elongation at break, measured with the crosshead displacement of the tensile machine, was found for short specimens deformed at strain rates in the order of $10^{-3} \mathrm{~s}^{-1}$ and $10^{-1} \mathrm{~s}^{-1}$. This is likely explained by the highest thickness-to-width ratio of the short specimens. While the different specimen geometries yield different absolute values of elongation at break, the change in strain to failure is similar for both geometries and materials between strain rates of $10^{-3} \mathrm{~s}^{-1}$ and $10^{-1} \mathrm{~s}^{-1}$. Therefore, the effect of strain rate on the ductility of the short specimens, from $2.0 \times 10^{-3}$ to $\sim 1600 \mathrm{~s}^{-1}$, can reasonably be extrapolated to the standardized geometry.

Due to the high ductility of the materials it is difficult to accurately measure the cross-sectional area of the broken specimens, so the area reduction at failure $(\mathrm{A} \%)$ is not used to quantify the ductility of the materials [53]. Also, measuring the elongation at break by aligning the broken specimens, as specified in ASTM's E8 standard [38], is difficult due to the non-standardized geometry and, again, the high ductility of both materials. The nominal strain to failure $\left(\varepsilon_{f}\right)$, defined as the elongation measured using DIC for the last frame before specimen failure $\left(\Delta y_{D I C}\right)$ divided by the initial gage length $\left(L_{0}\right)$ of approximately $5 \mathrm{~mm}\left(\varepsilon_{f}=\Delta y_{D I C} / L_{0}\right)$, is used. The last frame was selected based on a visual criterion. The specimen was considered to be broken when a translation of the specimen in the neck perpendicular to the loading direction was observed, even if both ends of the specimen still looked attached. The absolute values of nominal strain to failure are not intrinsic to each material, but the variation across approximately 7 orders of magnitude of strain rate provides valuable information for high-speed sheet forming of SRF cavities.

Figure 9 shows the nominal strain to failure as function of strain rate for short OFE copper and niobium welded specimens. Similar to the variation in yield and tensile strengths with strain rate (Fig. 8a and b), the nominal strain to failure is almost constant between $2.0 \times 10^{-3} \mathrm{~s}^{-1}$ and $\sim 1600 \mathrm{~s}^{-1}$ for EB welded OFE copper (the mean and standard deviation of $\varepsilon_{f}$ for all strain rates are equal to 0.75 and 0.01 , respectively). The ductility of niobium is lower, less repeatable between tests performed at the same strain rate, and more strain rate sensitive than OFE copper. Average maximum and minimum nominal strain to failures of $0.74 \pm 0.03$ and $0.61 \pm 0.03$ were measured at strain rates of $2.0 \times 10^{-2} \mathrm{~s}^{-1}$ and $400 \mathrm{~s}^{-1}$, respectively.

Peroni and Scapin [46] reported a relative reduction in strain to failure of about $20 \%$ between strain rates of $10^{-1} \mathrm{~s}^{-1}$ and $10 \mathrm{~s}^{-1}$ for unwelded high-purity niobium (calculated using the engineering strain at an engineering stress of zero at the end of the published stress-strain curves). EB welded specimens deformed at the same order of magnitude of strain rate showed a similar relative reduction in nominal strain to failure of approximately $15 \%$. The increase in strain rate between quasi-static and intermediate rates is then reducing the ductility of welded and unwelded high-purity niobium. A reduction in ductility varying from 16 to $50 \%$ was also 


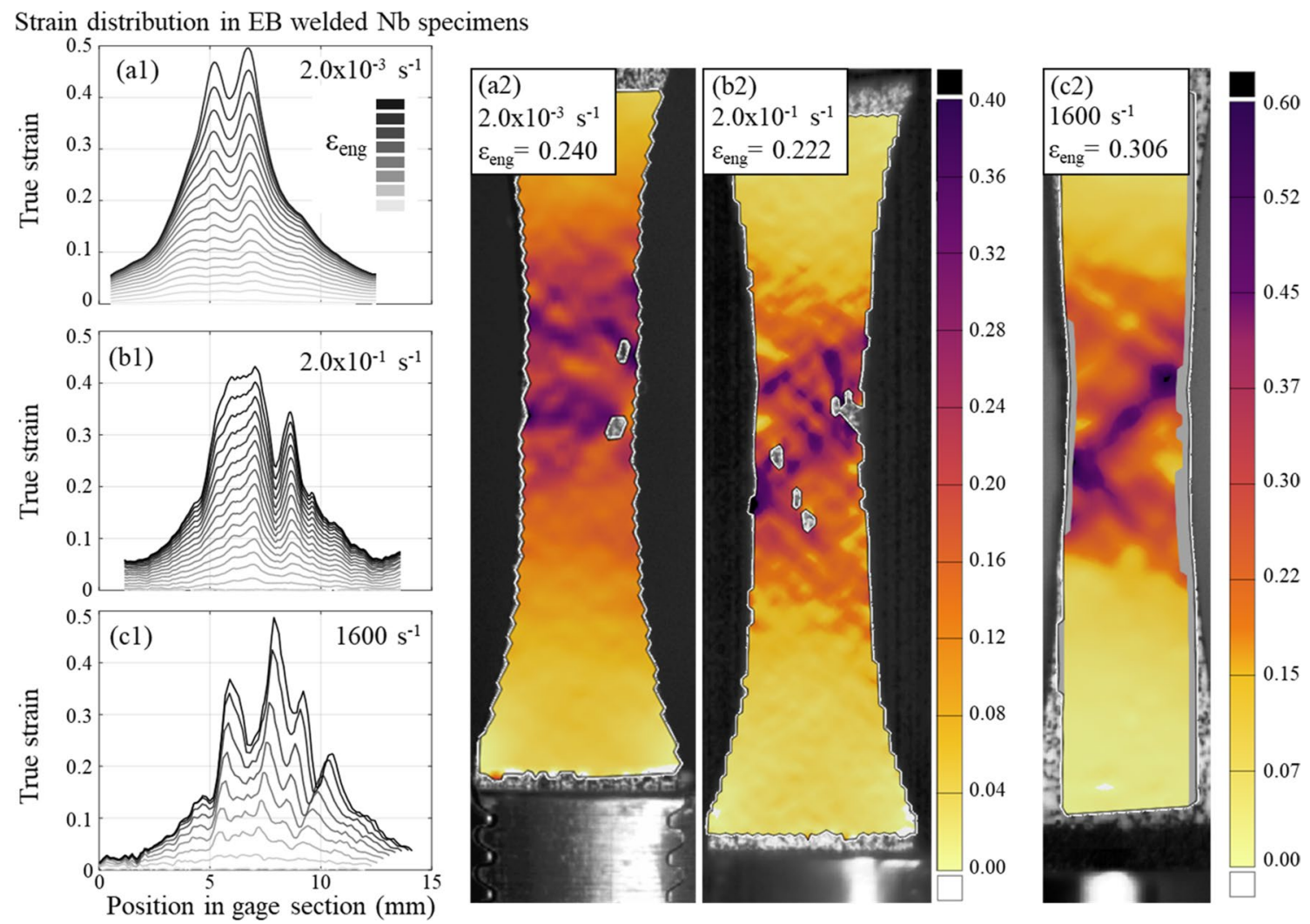

Fig. 10 Axial strain distribution along the centerline of the gage section of the short EB welded niobium specimens for increasing engineering strain and spatial strain distribution from DIC at strain rates of a1, a2 $10^{-3} \mathrm{~s}^{-1}, \mathbf{b 1}, \mathbf{b 2} 2.0 \times 10^{-1} \mathrm{~s}^{-1}$, and c1, c2 $\sim 1600 \mathrm{~s}^{-1}$

reported by Croteau et al. [47] for niobium single crystals with different crystallographic orientations deformed at strain rates of $10^{-2} \mathrm{~s}^{-1}$ and $\sim 10 \mathrm{~s}^{-1}$.

The nominal strain to failure for the welded niobium specimens deformed at $1600 \mathrm{~s}^{-1}$ is higher than for specimens deformed at $20 \mathrm{~s}^{-1}$ and $\sim 400 \mathrm{~s}^{-1}$. The cause of the increase in ductility when the strain rate goes from $\sim 400$ to $\sim 1600 \mathrm{~s}^{-1}$ is unknown, but it could be due to inertia effects that yield a stabilizing effect and enhance the ductility at very high strain rate [24]. However, the ductility remains lower than at quasi-static strain rates, which could be detrimental for highspeed sheet forming. Nevertheless, strain rates achieved in high-speed forming operations are generally larger than the maximal strain-rate considered in the present experiments. This can contribute to enhance inertia effects and the resulting formability improvement $[54,55]$. Moreover, in highspeed sheet forming, part of the deformation takes place during the impact of the sheet on the die. This phenomenon also contributes to enhance formability $[25,56]$.

\section{Strain Heterogeneities and Necking}

Figure 10 shows the true (logarithmic) axial strain distribution in EB welded niobium specimens (short geometry) deformed at nominal strain rates of $2.0 \times 10^{-3} \mathrm{~s}^{-1}$, $2.0 \times 10^{-1} \mathrm{~s}^{-1}$, and $\sim 1600 \mathrm{~s}^{-1}$. The axial true strain line scan in the gage section shown in Fig. 10a1, b1, and c1 reveal a region of lower strain close to the center of the specimen and surrounded by two peaks. This behavior is probably due to microstructural heterogeneity in the vicinity of the weld. The large strain heterogeneities, compared with OFE copper in Fig. 11, suggest that the anisotropic properties in the large niobium grains in the center of the specimen, as shown in Fig. 5b, affect the localization process. Moreover, Fig. 5b shows that the grain size is larger in the HAZ than in the fusion zone. These grain size heterogeneities may be responsible for the two peaks observed in the strain distribution (Fig. 10). In contrast, the more homogeneous strain distribution in OFE copper specimens are probably due to the more homogeneous grain size distribution. Note that plastic flow localization takes place near the center of the specimens for both materials and at all strain rates. It is believed that this phenomenon is due to the presence of the weld (and not to the rather short specimen length) as it also occurs with the long specimens. Figure 12 shows a comparison of the true strain distribution in the gage length between long and short specimens deformed at strain rates in the order of $10^{-3} \mathrm{~s}^{-1}$. The neck appears to be skewed to the right side of the gage 
Strain distribution in EB welded $\mathrm{Cu}$ specimens
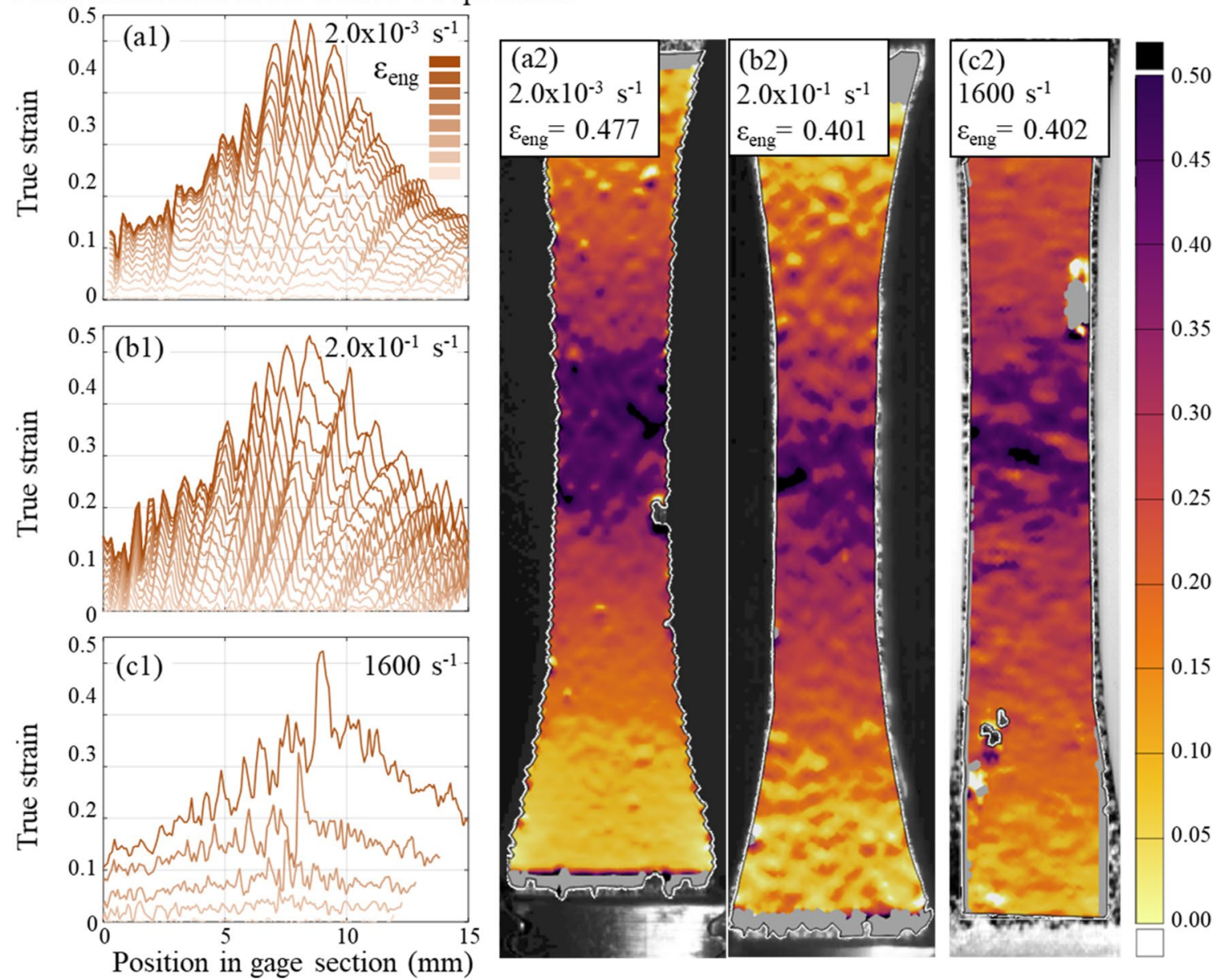

Fig. 11 Axial strain distribution along the centerline of the gage section of the short EB welded copper specimens for increasing engineering strain and spatial strain distribution from DIC at strain rates of $\mathbf{a 1}, \mathbf{a 2} 2.0 \times 10^{-3} \mathrm{~s}^{-1}, \mathbf{b 1}, \mathbf{b 2} 2.0 \times 10^{-1} \mathrm{~s}^{-1}$, and $\mathbf{c 1}, \mathbf{c 2} \sim 1600 \mathrm{~s}^{-1}$
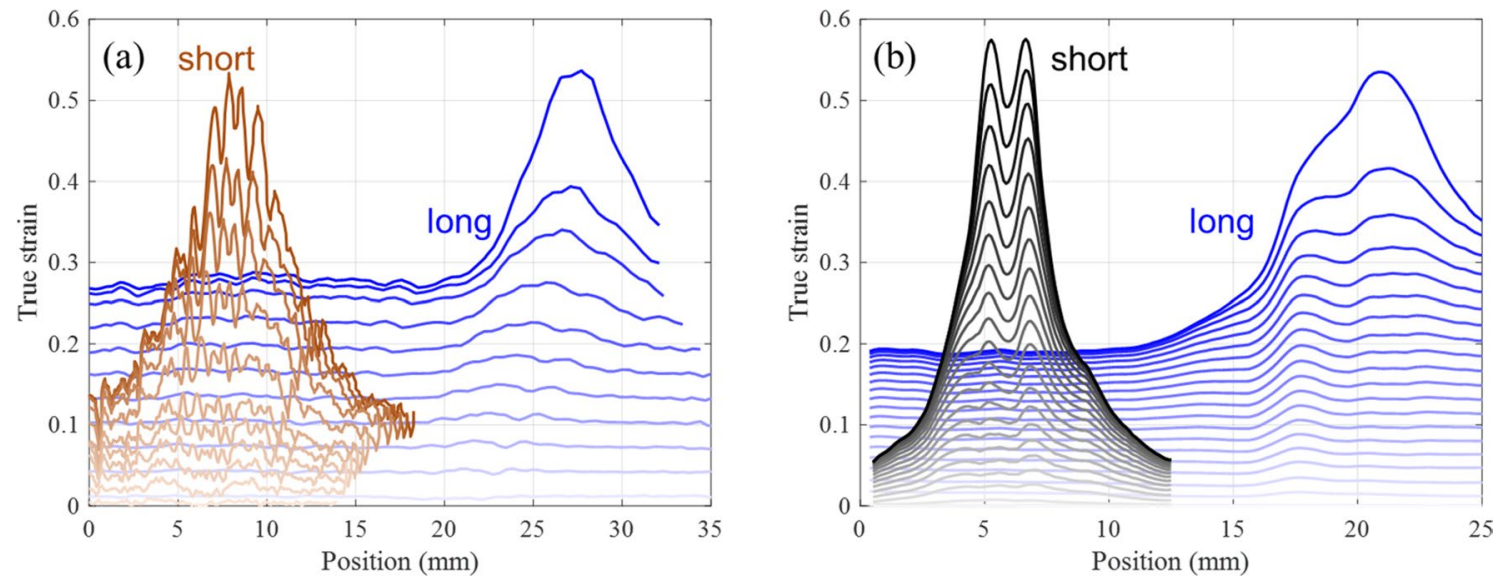

Fig. 12 Axial strain distribution in the gage length of long and short $\mathbf{a}$ OFE copper and $\mathbf{b}$ niobium specimens deformed at strain rates in the order of $10^{-3} \mathrm{~s}^{-1}$ 
Fig. 13 In-situ images of OFE copper and niobium during necking and at fracture for tests performed on (top) long and (bottom) short specimens deformed at nominal strain rates in the order of $10^{-3} \mathrm{~s}^{-1}$
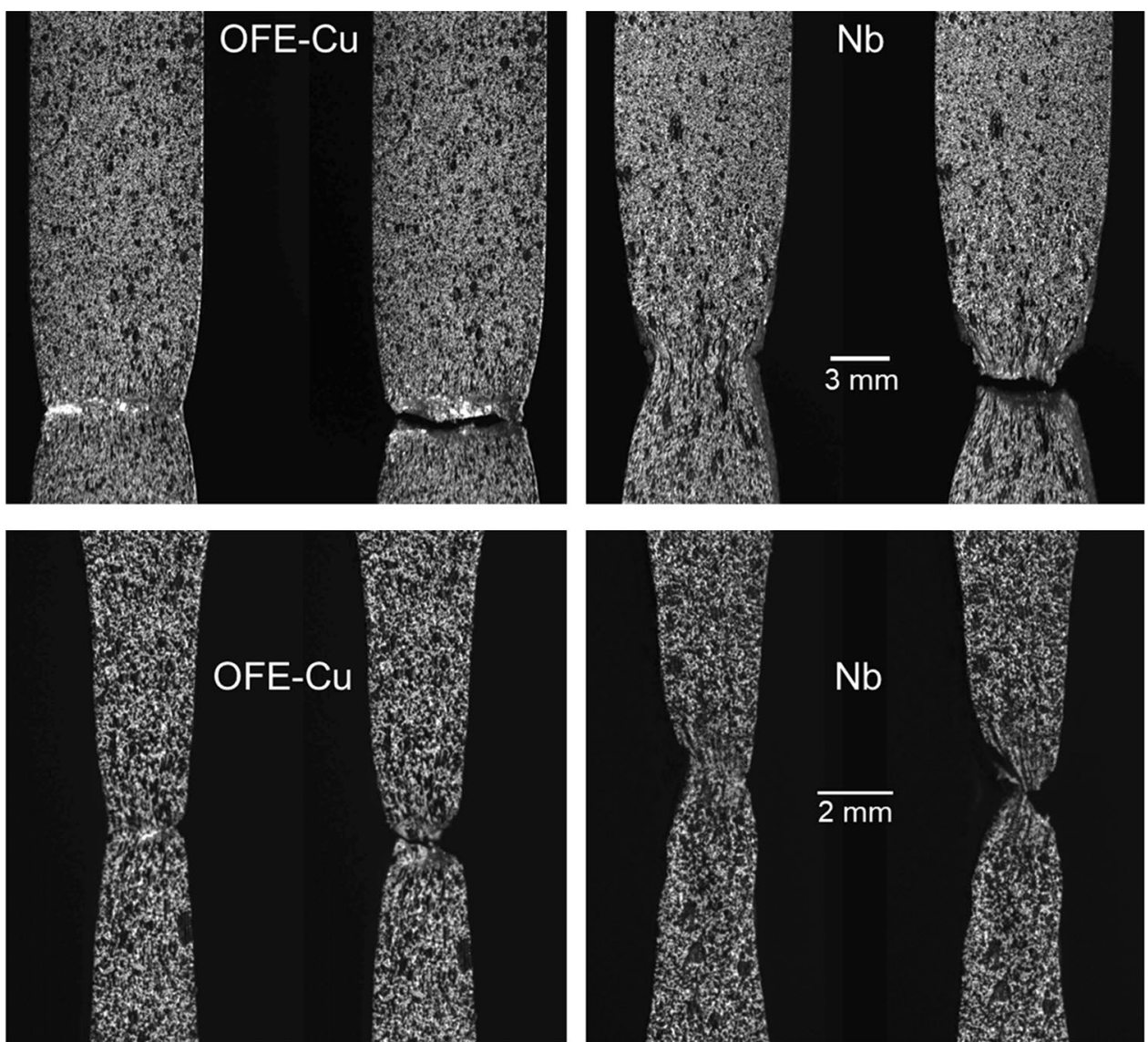

length (corresponding to the upper-half of the specimen, which is closer to the moving end of the tensile machine) for the long specimens due to a reduced field of view to capture details in the fracture at a high resolution. However, fracture occurred at the center of the specimen at all strain rates for both materials. This suggests that the weld acts as an imperfection that promotes plastic flow localization in its vicinity.

The true strain peaks and valley around the center of the short niobium specimen (Fig. 10), which was attributed to grain size heterogeneities, is not as pronounced for the long niobium specimen (which has a larger width). The influence of the weld on the mechanical properties seems to be more important for the short niobium specimens. This is probably because size effects from the large grains in the fusion region begin to be apparent (at the scale of the short specimen). Based on the grain size measured in the fusion zone in "Hardness Measurements and Microstructure Analysis" section, there are approximately 3 to 6 grains across the width of the short specimens compared with about 10 to 100 grains for the long specimens.

Figure 13 shows long and short OFE copper and niobium specimens deformed at strain rates in the order of
$10^{-3} \mathrm{~s}^{-1}$ during necking and after failure. Those pictures were acquired in-situ and used in the digital image correlation analyses. The long niobium specimen shows a more acute neck (the section reduction is more marked) and a narrower fracture surface than the long copper specimen. This indicates larger plastic strain in the neck of niobium specimens after the onset of localization, which suggests that niobium is intrinsically more ductile than OFE copper (the local strain to failure, at the center of the neck, is larger for niobium than for OFE copper ${ }^{1}$ ). The difference in dimensions in the gage section of the short and long specimens (e.g. higher thickness-to-width ratio for the short specimen) resulted in different neck morphologies for both materials. The short OFE copper specimen has a narrower fracture surface than the long one and a non-symmetric neck is observed in the short niobium specimen. The latter is probably caused by material heterogeneities and anisotropic properties at the center of the specimen from the low amount of grains across the width and thickness of the specimens. During

\footnotetext{
1 The local strain to failure (at the neck center) should not be confused with the nominal failure strain (Fig. 9). The latter corresponds to an average strain between two points of the specimen. It does not characterize only the failure of the material, but also the plastic flow localization process.
} 
the manufacturing of SRF cavities, the size effects should be negligible due to the large sheet dimensions and a more uniform strain distribution (Fig. 12b) is expected.

\section{Conclusion}

The tensile mechanical properties of electron beam welded oxygen-free electronic copper and high-purity niobium were measured at strain rates of $10^{-3} \mathrm{~s}^{-1}$ to $\sim 1600 \mathrm{~s}^{-1}$. The effects of the weld and the strain rate on the strength and ductility of both materials were reported.

For niobium, similar yield and tensile strengths were reported for EB welded and unwelded specimens for strain rates lower or equal to $20 \mathrm{~s}^{-1}$. At the highest strain rate, the strength of the unwelded specimen was higher. A reduction in ductility was measured at strain rates larger than $2.0 \times 10^{-1} \mathrm{~s}^{-1}$ and reached a minimum value at about $400 \mathrm{~s}^{-1}$. Large grains (up to $1200 \mu \mathrm{m}$ ) were measured in the fusion zone of the niobium specimens and this likely explains the lower reproducibility of the nominal strain to failure for this material.

For copper, the yield and tensile strengths of EB welded specimens were nearly constant over all strain rates studied and similar to unwelded specimens. The ductility, measured with the nominal strain to failure, was also similar at strain rates between $2.0 \times 10^{-3} \mathrm{~s}^{-1}$ to about $1600 \mathrm{~s}^{-1}$.

The effect of specimen geometry was studied and anisotropic effects are more important for short niobium specimens due to the low amount of grains through the thickness and width of the gage section. However, the same trends in strength and ductility were observed for standardized and short specimens, which validates the use of the short specimen at high strain rates to measure the effect of strain rate on welded specimens.

Acknowledgements This Marie Sklodowska-Curie Action (MSCA) Innovative Training Network (ITN) receives funding from the European Union's H2020 Framework Programme under grant agreement no. 764879. The experimental data used in this research were generated through access to the ELSA HopLab under the Framework of access to the Joint Research Centre Physical Research Infrastructures of the European Commission (DWAM project, Research Infrastructure Access Agreement Nr. 35509-1/2019-1-RD-ELSA-HopLab). The authors also want to acknowledge Derek Siu of the Imperial College London for the tests on unwelded annealed OFE-Cu at strain rates between $\sim 1 \mathrm{~s}^{-1}$ and $100 \mathrm{~s}^{-1}$, used as comparison with the results of this study and Manuel Redondas Monteserin of CERN (EN-MME) for welding the sheets.

Author contributions J-FC: Conceptualization, Methodology, Formal analysis, Writing-Original Draft, Writing-Review \& Editing, Visualization. MP: Conceptualization, Methodology, Investigation, Formal analysis, Data curation, Writing-Review \& Editing, Visualization, Resources. SA: Resources, Supervision, Funding acquisition. NJ: Formal analysis, Writing-Review \& Editing, Supervision. EC:
Conceptualization, Methodology, Writing-Review \& Editing, Supervision, Funding acquisition, Project administration.

Funding European Union's H2020 Framework Programme Grant Agreement No. 764879.

Data Availability Data reported in the manuscript are available upon request to the corresponding author.

\section{Compliance with Ethical Standards}

Conflict of interest The authors declare that they have no known competing financial interests or personal relationships that could have appeared to influence the work reported in this paper.

Open Access This article is licensed under a Creative Commons Attribution 4.0 International License, which permits use, sharing, adaptation, distribution and reproduction in any medium or format, as long as you give appropriate credit to the original author(s) and the source, provide a link to the Creative Commons licence, and indicate if changes were made. The images or other third party material in this article are included in the article's Creative Commons licence, unless indicated otherwise in a credit line to the material. If material is not included in the article's Creative Commons licence and your intended use is not permitted by statutory regulation or exceeds the permitted use, you will need to obtain permission directly from the copyright holder. To view a copy of this licence, visit http://creativecommons.org/licenses/by/4.0/.

\section{References}

1. Padamsee H, Knobloch J, Hays T (2008) RF superconductivity for accelerators, 2nd edn. Wiley-VCH, Weinheim

2. Chiaveri E, Lengeler H (1984) Welding of Nb cavities at CERN. Paper presented at the SRF84, Geneva, Switzerland. https://accel conf.web.cern.ch/srf84/papers/srf84-33.pdf

3. Wu G et al (2010) Investigations of surface quality and SRF cavity performance. In: FERMILAB-CONF-10-430-TD, Batavia, USA, pp 1-4. https://lss.fnal.gov/archive/2010/conf/fermilab-conf-10430-td.pdf

4. ATLAS Collaboration (2012) Observation of a new particle in the search for the Standard Model Higgs boson with the ATLAS detector at the LHC. Phys Lett B 716(1):1-29. https://doi. org/10.1016/j.physletb.2012.08.020

5. Yamanaka M, Inoue H, Shimizu H, Umemori K (2015) Hydroforming SRF cavities from seamless niobium tubes. In: SRF 2015, Whistler, Canada, pp 1176-1180

6. Singer W, Singer X, Jelezov I, Kneisel P (2015) Hydroforming of elliptical cavities. Phys Rev Spec Top Accel Beams. https://doi. org/10.1103/PhysRevSTAB.18.022001

7. Kirchgessner JL (1987) Forming and welding of niobium for superconducting cavities. In: The third workshop on RF superconductivity. Argonne National Laboratory, pp 533-544

8. Hauviller C (1989) Fully hydroformed RF cavities. In: Proceedings of the 1989 IEEE particle accelerator conference, 'Accelerator Science and Technology', pp 485-487. https://doi.org/10.1109/ PAC.1989.73087

9. Dujardin S, Genest J, Hauviller C, Jaggi R, Jean-Prost B (1990) Hydroforming monolithic cavities in the $300 \mathrm{MHz}$ range. In: Proceedings of 2 nd European particle accelerator conference (EPAC 90), pp 1100-1102 
10. Palmieri V, Kulik II, Preciso R, Ruzinov VL, Stark SY (1994) A new method for forming seamless $1.5 \mathrm{GHz}$ multicell cavities starting from planar disks, pp 2212-2214

11. Fujino T et al (1995) Status of the seamless L-band cavity fabrication at KEK. In: 1995 Workshop on RF superconductivity, Gif-sur-Yvette, France, pp 741-745

12. Antoine C, Gaiffier J, Chalaye H (1997) Hydroforming at C.E.A. Saclay: first results. In: 1997 Workshop on RF superconductivity, Padova, Italy, pp 598-605

13. Singer W, Kaiser H, Singer X, Weichert G (2001) Hydroforming of superconducting TESLA cavities. In: 10th Workshop on RF superconductivity, Tsukuba, Japan, pp 170-176

14. Compton $C$ et al (2007) Studies of alternative techniques for niobium cavity fabrication. SRF 2007. Beijing, China, pp 429-433

15. Kaiser H, Singer W, Singer X (1999) Hydroforming of back extruded niobium tubes, Santa Fe, pp 528-531. https://accelconf. web.cern.ch/SRF99/papers/wep042.pdf

16. Gonin I, Jelezov I, Kaiser H, Singer W (1997) Hydroforming test of back extruded niobium tube. In: 1997 Workshop on RF superconductivity, Padova, Italy, pp 590-597

17. Crooks R (2012) Fabrication and testing of ILC cavities produced from seamless $\mathrm{Nb}$ tubes. Paper presented at the Fifth international workshop on thin films and new ideas for pushing the limits of RF superconductivity, Newport News, VA, July 2012

18. Crooks R (2009) Production of seamless superconducting radio frequency cavities from ultra-fine grained niobium. Black Laboratories, L.L.C., SBIR DE-FG02-04ER83909, November 2009

19. Balachandran S, Elwell RC, Kang D, Barber RE, Bieler TR, Hartwig KT (2013) Nb tubes for seamless SRF cavities. IEEE Trans Appl Supercond 23(3):7100904. https://doi.org/10.1109/ TASC.2013.2243492

20. Balachandran S (2015) Microstructure development in bulk niobium following severe plastic deformation and annealing. $\mathrm{PhD}$ Thesis, Texas A\&M University, College Station

21. Palmieri V (1997) Seamless cavities: the most creative topic in RF superconductivity. In: 1997 Workshop on RF superconductivity, Padova, Italy, pp 553-589

22. Mapar A, Bieler TR, Pourboghrat F, Compton CC, Murphy JE (2015) Hydroforming of large grain niobium tube. In: SRF 2015, Whistler, Canada, pp 1171-1175. http://accelconf.web.cern.ch/ SRF2015/papers/thpb040.pdf

23. Balanethiram VS, Daehn GS (1994) Hyperplasticity: increased forming limits at high workpiece velocity". Scr Metall Mater 30(4):515-520. https://doi.org/10.1016/0956-716X(94)90613-0

24. Hu X, Daehn GS (1996) Effect of velocity on flow localization in tension. Acta Mater 44(3):1021-1033. https://doi. org/10.1016/1359-6454(95)00228-6

25. Imbert JM, Winkler SL, Worswick MJ, Oliveira DA, Golovashchenko S (2005) The effect of tool-sheet interaction on damage evolution in electromagnetic forming of aluminum alloy sheet. J Eng Mater Technol 127(1):145-153. https://doi. org/10.1115/1.1839212

26. Golovashchenko S, Imbert JM, Worswick MJ (2006) Contributing factors to the increased formability observed in electromagnetically formed aluminum alloy sheet. In: 2 nd international conference on high speed forming, Dortmund, Germany, March 2006, pp 3-12. https://doi.org/10.17877/DE290R-12925

27. Atieh S (2020) Novel technologies applied to SRF (cavity) fabrication. Paper presented at the TTC 2020, Geneva, Switzerland, 05 February 2020. https://indico.cern.ch/event/817780/contributi ons/3716472/

28. Cantergiani E et al (2016) Niobium superconducting rf cavity fabrication by electrohydraulic forming. Phys Rev Accel Beams. https://doi.org/10.1103/PhysRevAccelBeams.19.114703

29. Jiang H, Bieler TR, Compton C, Grimm TL (2003) Mechanical properties, microstructure, and texture of electron beam butt welds in high purity niobium. In: Proceedings of the 2003 bipolar/BiCMOS circuits and technology meeting (IEEE Cat. No. 03CH37440), Portland, OR, USA, vol. 2, 2003, pp 1359-1361. https://doi.org/10.1109/PAC.2003.1289705

30. Lee H, Kim C, Song J (2015) An evaluation of global and local tensile properties of friction-stir welded DP980 dual-phase steel joints using a digital image correlation method. Materials 8(12):8424-8436. https://doi.org/10.3390/ma8125467

31. ASTM International ASTM B170-99(2015) Standard specification for oxygen-free electrolytic copper-refinery shapes. ASTM, West Conshohocken. https://doi.org/10.1520/B0170-99R15

32. Geng RL, Knobloch J, Padamsee H (1999) Micro-structures of RF surfaces in the electron-beam-weld regions of niobium. In: 1999 workshop on RF superconductivity, Padova, Italy, pp 238-245

33. Schmidt A et al (2010) $1.3 \mathrm{GHz}$ niobium single-cell fabrication sequence. TTC Report 2010-01

34. Brawley J, Mammosser J, Phillips L (1997) Electron beam weld parameter set development and cavity cost. In 1997 Workshop on RF superconductivity, Padova, Italy, pp 518-522

35. Demyanov SE et al (2015) (2015) Superconducting properties of ultra-pure niobium welded joints. Low Temp Phys 41(7):522527. https://doi.org/10.1063/1.4927078

36. International Organization for Standardization (2012) ISO 4136:2012 - Destructive tests on welds in metallic materialstransverse tensile test. https://www.iso.org/standard/62317.html

37. Carra F (2015) Crab cavity and cryomodule development for HL-LHC. In: SRF2015, pp 1460-1467

38. ASTM International (2016) ASTM E8/E8M-16ae1, Standard test methods for tension testing of metallic materials. astm.org

39. Peroni M, Caverzan A, Solomos G (2016) A new apparatus for large scale dynamic tests on materials. Exp Mech 56(5):785796. https://doi.org/10.1007/s11340-015-0123-0

40. Peroni M, Solomos G (2019) Advanced experimental data processing for the identification of thermal and strain-rate sensitivity of a nuclear steel. J Dyn Behav Mater 5(3):251-265. https:// doi.org/10.1007/s40870-019-00207-w

41. Bussac M-N, Collet P, Gary G, Othman R (2002) An optimisation method for separating and rebuilding one-dimensional dispersive waves from multi-point measurements. Application to elastic or viscoelastic bars. J. Mech. Phys. Solids 50(2):321349. https://doi.org/10.1016/S0022-5096(01)00057-6

42. Peroni M, Solomos G, Babcsan N (2016) Development of a Hopkinson bar apparatus for testing soft materials: application to a closed-cell aluminum foam. Materials 9(1):27. https://doi. org/10.3390/ma9010027

43. Satish R, Seshagiri Rao V, Ananthapadmanaban D, Ravi B (2016) Tensile strength and hardness correlations with microscopy in friction welded aluminum to copper. J Inst Eng India Ser C 97(1):121-126. https://doi.org/10.1007/s40032-015-0187-8

44. Kapadia P et al (2017) Quantification of residual stresses in electron beam welded fracture mechanics specimens. Int $\mathrm{J}$ Solids Struct 106-107:106-118. https://doi.org/10.1016/j.ijsol str.2016.11.028

45. Huber N, Heerens $\mathbf{J}$ (2008) On the effect of a general residual stress state on indentation and hardness testing. Acta Mater 56(20):6205-6213. https://doi.org/10.1016/j.actam at.2008.08.029

46. Peroni L, Scapin M (2018) Experimental analysis and modelling of the strain-rate sensitivity of sheet niobium. In: EPJ Web conference, vol 183. https://doi.org/10.1051/epjconf/201818301014.

47. Croteau J-F et al (2020) Effect of strain rate on tensile mechanical properties of high-purity niobium single crystals for SRF applications. Mater Sci Eng A. https://doi.org/10.1016/j. msea.2020.140258

48. Ragu Nathan S, Balasubramanian V, Malarvizhi S, Rao AG (2015) Effect of welding processes on mechanical and microstructural 
characteristics of high strength low alloy naval grade steel joints. Def Technol 11(3):308-317. https://doi.org/10.1016/j. dt.2015.06.001

49. Cavaliere P, Campanile G, Panella F, Squillace A (2006) Effect of welding parameters on mechanical and microstructural properties of AA6056 joints produced by Friction Stir Welding. J Mater Process Technol 180(1-3):263-270. https://doi.org/10.1016/j.jmatp rotec.2006.06.015

50. Rosenberg Z, Kositski R, Ashuach Y, Leus V, Malka-Markovitz A (2019) On the upturn phenomenon in the strength vs. strain-rate relations of metals. Int J Solids Struct 176-177:185-190. https:// doi.org/10.1016/j.ijsolstr.2019.06.015

51. Wei Q, Cheng S, Ramesh KT, Ma E (2004) Effect of nanocrystalline and ultrafine grain sizes on the strain rate sensitivity and activation volume: fcc versus bcc metals. Mater Sci Eng A 381(12):71-79. https://doi.org/10.1016/j.msea.2004.03.064

52. Zerilli FJ, Armstrong RW (1990) Description of tantalum deformation behavior by dislocation mechanics based constitutive relations. J Appl Phys 68(4):1580-1591. https://doi. org/10.1063/1.346636
53. Davis JR (ed) (2004) Tensile testing, 2nd edn. Materials Park, ASM International

54. Rohatgi A, Soulami A, Stephens EV, Davies RW, Smith MT (2014) An investigation of enhanced formability in AA5182-O Al during high-rate free-forming at room-temperature: Quantification of deformation history. J Mater Process Technol 214(3):722-732. https://doi.org/10.1016/j.jmatprotec.2013.07.015

55. Jacques N (2020) An analytical model for necking strains in stretched plates under dynamic biaxial loading. Int J Solids Struct 200-201:198-212. https://doi.org/10.1016/j.ijsolstr.2020.05.028

56. Golovashchenko SF, Gillard AJ, Mamutov AV (2013) Formability of dual phase steels in electrohydraulic forming. J Mater Process Technol 213(7):1191-1212. https://doi.org/10.1016/j.jmatprotec .2013 .01 .026

Publisher's Note Springer Nature remains neutral with regard to jurisdictional claims in published maps and institutional affiliations. 